\title{
An Analysis of Characteristics of Traditional Architectural Settlement of Dongxiang Nationality
}

\author{
Hai-Chen ZHENG ${ }^{1,2^{*}, \mathrm{a}}$, Jun-Feng SUO ${ }^{1,2, \mathrm{~b}}$, Yi-Jie CAO ${ }^{1,2, \mathrm{c}}$, Zhuang LIU LI,2,d $^{1, \mathrm{~d}}$ \\ ${ }^{1}$ School of Civil Engineering in Northwest University for Nationalities, Lanzhou 730030, China \\ ${ }^{2}$ Key Laboratory of New Laboratory of New Building Materials and Building Energy-saving of Gansu \\ Province Lanzhou 730030, China \\ aZhenghaichen1@163.com, b15006102@qq.com, cj036@163.com, d349339@sina.com \\ ${ }^{*}$ Corresponding author
}

Keywords: Architectural Settlement, Spatial Pattern, Architectural Style.

\begin{abstract}
The outlook of Dongxiang area in Gansu province has been experiencing rapid changes with the acceleration of urbanization in recent years. A study needs to be conducted on local traditional architectural settlement to figure out how to realize "localization of modern architecture and modernization of vernacular architecture" [1] in this region. The research group uses graphics to analyze and tease the spatial pattern and architectural style of local traditional architectural settlement from the perspective of architectonics and landscape science based on field research. It will provide reference for urban and rural construction in the future.
\end{abstract}

\section{Introduction}

The important cultural phenomenon of mankind is carried and embodied in architectural settlement. Different nationalities have different settlement forms even if they live in the same natural conditions and social customs while the spatial construction of settlement of the same nationality is identical whether they live in the same natural conditions and social customs or not[2]. Dongxiang nationality is one of the nationalities peculiar to Gansu, China. They mainly live in piedmont belt in the western area of the Taohe River, the eastern area of Daxia River and the southern area of Yellow River in Gansu Province. With the acceleration of urbanization in recent years, outlook of this area is experiencing rapid changes. Conservation and development seem to be inherent contradiction to minority areas, which are concerned with religious custom and cultural characteristics in national minorities. How to realize this dialectical benign development of "localization of modern architecture and modernization of vernacular architecture"[1] in this region need construction workers to carefully explore historical experience with which predecessors build their home and comprehend deep connotation of aspects such as settlement formation and base consolidation. For such purpose, the research groups penetrate into the Dongxiang area for onsite investigation during the 2012 and 2013 summer vacations and analyze characteristics of traditional architectural settlement in Dongxiang nationality through recording an dorganizingrelated information.

\section{Spatial Form of Traditional Architectural Settlement of Dongxiang Nationality}

Spatial form of villages can be regarded as revised results of people's place of residence. Dongxiang nationality people call themselves "Sarta (which means merchants)". They believe in Islam and live in clan. They may be merchants or farmers.

\section{Adaptability of Spatial Form of Villages to Geographical Conditions}

The overall form of traditional settlements is generally restricted more by natural scenery pattern. With a square-round shape, Dongxiang Autonomous County is surrounded by river on three sides. Seen from Fig.1, it is high and steep, hilly and gully-crossing surrounded by river on three sides. Thus, 80 percent of its land is dry and mountainous [3]. Most of its loess geomorphy is hills and 
tableland. The terrain is broken, the ups and downs of which are frequent and well-distributed. Water is an important factor for the curbs construction and development of local people.

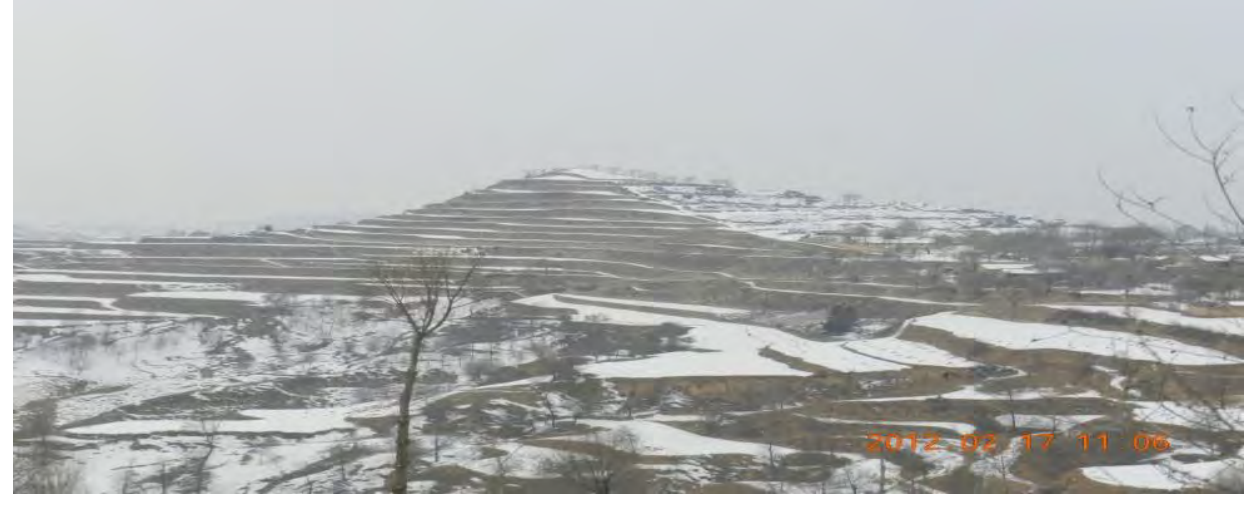

Fig. 1The Steep Slope of Loess Plateau and Its Cracked Loess Geomorphy

\section{Characteristics of Spatial Form of Villages}

Dongxiang nationality is a nationality with strong clan awareness and devout belief. Traditional villages with blood relationship and religious relations as the bond tend to be closed and stable. They have continuity towards tradition and strong awareness of belief [4].

The spirit of Islam permeates into heart of Muslims with mosque as the medium. They also do Islamic prayer and worship Allah through mosque [5]. Traditional settlement of Dongxiang nationality is the core-briquette-structure layout which usually takes mosque as its main core or the only core. It looks like net from regional and spatial projection. If there is only one core, the mosque must be the center. Its size is not big about several dozens of households. It was formed at the beginning or restricted by geographical conditions. If there are multi-cores, the main core is mosque and the other cores may be village committee, Beaconsfield and bleachery. The reason why multi-core forms is that the population of the settlement expands and splits from the group or people outside come to settle down here [6].

\section{Architectural Style}

Architecture of Dongxiang nationality is characterized by regionalism, historicality and national culturalism. In Dongxiang, the main architectures are folk house, mosque and Beaconsfield, most of which are traditional Chinese architectures. In terms of both the architecture style and the decoration characteristics, it displays the principle that Islamic culture is fundamental while traditional building technology is just for use, making the architectures full of Islamic cultural sentiment.

\section{Folk House}

The style of local folk house is simple and practical. Coming from the most direct life demands, traditional folk house tends not to be restricted by formulation, organizes space flexibly and freely and uses space effectively, fully demonstrating its adaptability to natural environment.

As to styles of folk house, there are cave-house, one-storey house, tile-roofed house and Tsuchidana. Traditional houses are mostly one-storey house. The main materials are earth and wood. And the structures are traditional Chinese timber frame and girder structure. Seen from Fig.2, the frame structure was formed with large timber components such as pillar, girder and purlin shoulders load, wind power and earthquake force from the roof. Embosom component of the outer wall is made of cob wall or clay brick. The roof is covered with clay tile such as Chinese-style tile, ridge tile and flat tile. Traditional folk house consists of uni-courtyard, triangle courtyard and quadrangle courtyard and so on. Seen from Fig.3, courtyards are mostly triangle courtyards, namely the northern room which is situated in the north and faces to the south, the western room which is situated in the west and faces to the east and the eastern room which is situated in the east and faces 
to the west. The southern area of the courtyard is usually orchard and vegetable field. The northern room is the main room, commonly known as the central room. It has three bays. The area separated from the central room by the peripheral column is called eaves gallery. The areas beyond the eaves are where the earthen beds lay. The central room is the place to welcome the guests and hold important ceremonies. The earthen beds on both sides are cool on summer and warm in winter and there is abundant sunshine. Therefore, the elder usually lives here. The western room is the habitable room. The kitchen is in the corner of the main room and the western room. The eastern room is the semi-enclosed corral. The rest room is in the corner of the main room and the eastern room, with the shape of the word "one". Seen from Fig.4, The architrave and the outrigger under the eaves are usually decorated with delicate wood carvings. Seen from Fig.5, Patterns of human beings and animals are forbidden in the interior decoration while Arabic couplets and "Kaaba" pictures are the most popular [7]. Emphasis on sanitation and hygiene and landscaping are the common features of folk house of Dongxiang nationality. There are bathroom and hanging cage (bucket) in every family for scouring bath at any time. Many households of Dongxiang nationality prefer to plant flowers and trees such as cockscomb, peony, pomegranate and rosebay in their courtyards.

Every eave of the gate of the courtyard is covered with tiles. And the downside of the eave is decorated with beautiful floral patterns. The doors are mostly wooden bipartings. The stand column is built with black bricks and decorated with tile craving. The local stones are used to make footstone under the column, step stone and gate pier.

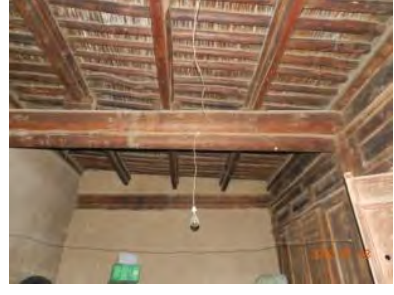

Fig.2 Typical Timber Frame

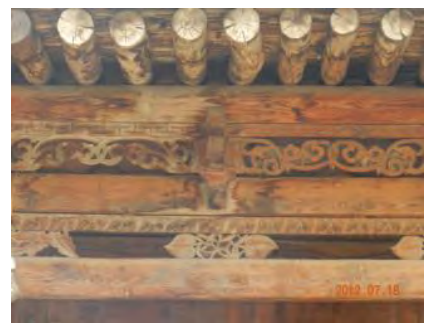

Fig.4 Delicate Wooden Cravings

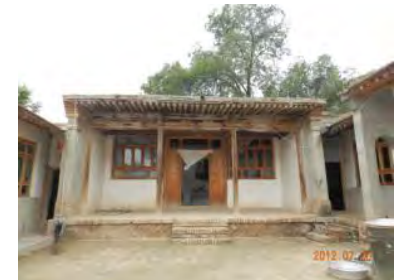

Fig.3 Three-bay Central Room with Eaves Galle

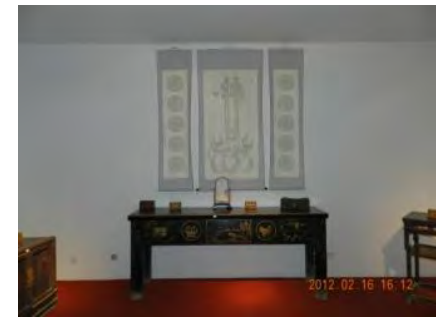

Fig.5 Arabic Couplets in the Central Room

\section{Mosque}

Mosques mostly adopt traditional timber frame (or replica timber frame) in villages of Dongxiang nationality. Its general layout is "three-halls- in one", namely integration of church, water hall and scripture hall. The church is in the middle while the water hall and the scripture hall are on the two sides respectively. Seen from Fig.6, the church is in the middle and the other two halls lay crosswise, forming courtyard group. A towering minaret is built at the gate of the mosque .The church consists of front porch, prayer hall and back kiln. The front porch is the transition zone where the Muslims take off their shoes. Its roof is mostly cornice with curly tent. The prayer hall is the highest place in the whole temple. The whole architecture is square which is situated in the west and faces to the east. Seen from Fig.7, the roof uses square log ridge with resting-on-the-top of-the-mountain style. Three groups of crescent mark pointing to the sky are laid on the middle of the roof. Such resting on the top of the mountain style is high-grade roof style, which ranks only the second to hip roof style in China. It indicates the honorable status of mosque in the heart of Muslims. The interior hall is grand and spacious and its decoration is solemn and 
simple. The mihrab is in the back kiln. Seen from Fig.8, the west walls are concave, taking mihrab of Medina prophet as the standard of its form. The back kiln can also be set up independently. It is about two or three layers with pavilion roof. The interior is made into various caissons by imitating onion dome [8].

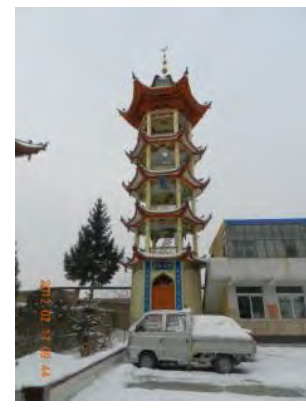

Fig. 6 The Towering Minaret

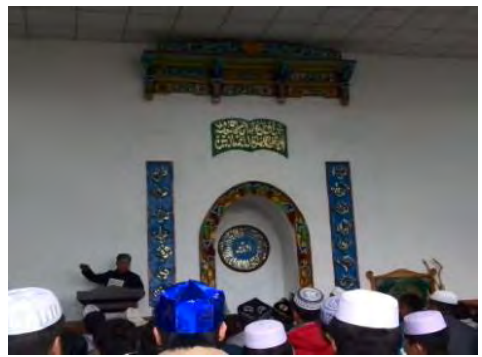

Fig.8 The Back Kiln with Concave Walls

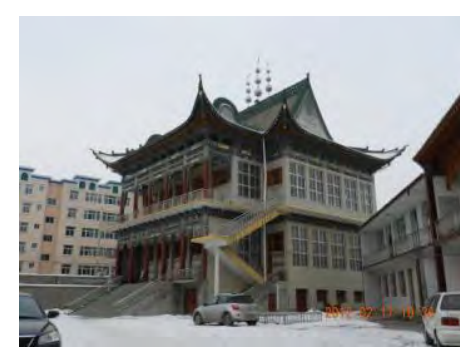

Fig. 7 The Resting-on-the-top of-the-mountain-style Church with Curly Tent

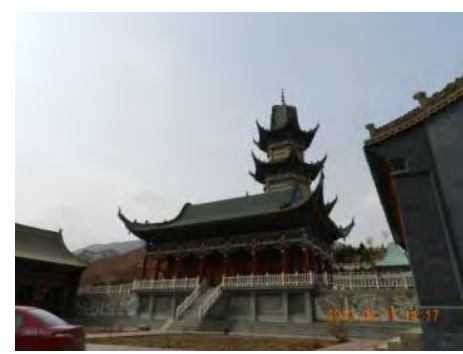

Fig.9.Beaconsfield, the Tomb Cottage is Three-storey with and Eight Divinatory Symbols

\section{Beaconsfield}

Beaconsfield should be built in places high and steep, distant from underground water and sparsely-populated with excellent geomancy. Its main or core architectures are tombs of the hierarchs and the oldest. Larger Beaconsfield compromising tombs of inheritors of Menhuan, memorial gate, prayer hall and tomb groups of missionary heirs and other annex are formed into the building group through hall combination. Among them, the Golden Top (the Eight Diagrams Tomb) is the main building. An ogival tomb is built on the square brick Beacons field. Seen from Fig.9, a valued vase is put on the roof to protect the building, which tends to be post and panel structure. There are three layers with eight diagrams, two layers with six diagrams and one layer with four diagrams. The front worshiping hall connected with the tombs is situated in the north and faces to the south while the buried skeletons face to the west. This design not only embodies localization of architectural culture but also shows the power of belief.

\section{Conclusion}

The traditional architectural settlement is the combined organism of natural environment, religious culture and construction inheritance. This area is confronted with serious spatial construction crisis due to lack of fundamental research during the local urbanization and construction of new countryside. Thus, this topic was come back again. It can be learned and used for reference characteristics of traditional architectural settlement formed in early times and still developing nowadays. Referential value can be provided through recording those disappearing wealth and deliberating internal characteristics.

\section{Acknowledgement}

This work was financially supported by the Fundamental Research Funds for the Central 
Universities (Project number: ZYZ2011083).

\section{References}

[1]Yun Wang: The space concept of the traditional settlement structure (China Building Industry Press, China, 2009).

[2]Liang-yong $\mathrm{Wu}$ : The architecture of the future ( Tsinghua University Press, China,1999).

[3]http://dance.jnu.edu.cn/MINORITY/index10.htm.

[4]Jin Duan: Space Research One ( Southeast University Press, 2006(3) ).

[5]Wei-lin Mian: The Introduction to Chinese Hui Islamic religious systems(Ningxia People's Publishing House, China,1997).

[6]Duan Jin: Space Research One ( Southeast University Press, 2006(3)).

[7]Picture 5 was shot in Museum of Dongxiang County.

[8]Yu-lan Qiu, Zhensheng Yu: Muslim Architecture in China (China Architecture \&Building Press, 1992(10)). 